University of Wollongong

Research Online

Australian Institute for Innovative Materials -

Papers

Australian Institute for Innovative Materials

$1-1-2014$

\title{
Applications of scanning electrochemical microscopy (SECM) for local characterization of AZ31 surface during corrosion in a buffered media
}

Sina S. Jamali

University of Wollongong, ssj198@uowmail.edu.au

Simon E. Moulton

University of Wollongong, smoulton@uow.edu.au

Dennis E. Tallman

North Dakota State University

Maria Forsyth

Deakin University

Jan Weber

Boston Scientific

See next page for additional authors

Follow this and additional works at: https://ro.uow.edu.au/aiimpapers

Part of the Engineering Commons, and the Physical Sciences and Mathematics Commons

Research Online is the open access institutional repository for the University of Wollongong. For further information contact the UOW Library: research-pubs@uow.edu.au 


\title{
Applications of scanning electrochemical microscopy (SECM) for local characterization of AZ31 surface during corrosion in a buffered media
}

\begin{abstract}
Different modes of scanning electrochemical mapping (SECM) such as surface generation/tip collection (SG/TC), amperometry, AC-SECM and potentiometry were employed to characterize the active/passive domains, hydrogen gas $(\mathrm{H} 2)$ evolution and local $\mathrm{pH}$ on a corroding surface of AZ31 in simulated biological fluid (SBF). It was found that the main domains of $\mathrm{H} 2$ evolution are associated with lower insulating properties of the surface as well as higher local $\mathrm{pH}$. The near surface $\mathrm{pH}$ was found to be highly alkaline indicating that, even in a buffered solution such as SBF, the local pH on a corroding AZ31 surface can be significantly different to the bulk $\mathrm{pH}$.
\end{abstract}

\section{Keywords}

az31, surface, applications, electrochemical, scanning, secm, characterization, local, during, microscopy, corrosion, media, buffered

\section{Disciplines}

Engineering | Physical Sciences and Mathematics

\section{Publication Details}

Jamali, S. S., Moulton, S. E., Tallman, D. E., Forsyth, M., Weber, J. \& Wallace, G. G. (2014). Applications of scanning electrochemical microscopy (SECM) for local characterization of AZ31 surface during corrosion in a buffered media. Corrosion Science, 86 93-100.

\section{Authors}

Sina S. Jamali, Simon E. Moulton, Dennis E. Tallman, Maria Forsyth, Jan Weber, and Gordon G. Wallace 


\title{
Applications of scanning electrochemical microscopy (SECM) for local characterization of AZ31 surface during corrosion in a buffered media
}

Sina S. Jamali ${ }^{1}$, Simon E. Moulton ${ }^{1}$, Dennis E. Tallman ${ }^{2}$, Maria Forsyth ${ }^{3}$, Jan Weber ${ }^{4}$, Gordon G. Wallace ${ }^{1 *}$

${ }^{1}$ Intelligent Polymer Research Institute, AIIM Facility, Innovation Campus, University of Wollongong, NSW Australia 2522, Tel: +61 24298 1443| Fax: +61 242213114

Emails: S.S.Jamali: ssj198@uowmail.edu.au, S.E. Moulton: smoulton@uow.edu.au, G.G. Wallace: gwallace@uow.edu.au

${ }^{2}$ Department of Coatings and Polymeric Materials, North Dakota State University, Fargo, ND 58108-6050, USA, Email: Dennis.Tallman@ndsu.edu

${ }^{3}$ Institute for Frontier Materials, Deakin University, Burwood Campus, Burwood, Victoria 3125, Australia, Email: maria.forsyth@deakin.edu.au

${ }^{4}$ Boston Scientific, G. Martinolaan 50, 6229 GS, Maastricht, Nederland, Email: jan.weber@bsci.com

Corresponding authors:

S.E. Moulton: smoulton@uow.edu.au

G.G. Wallace: gwallace@uow.edu.au

\begin{abstract}
Different modes of scanning electrochemical mapping (SECM) such as surface generation/tip collection (SG/TC), amperometry, AC-SECM and potentiometry were employed to characterise the active/passive domains, hydrogen gas $\left(\mathrm{H}_{2}\right)$ evolution and local $\mathrm{pH}$ on a corroding surface of AZ31 in simulated biological fluid (SBF). It was found that the main domains of $\mathrm{H}_{2}$ evolution are associated with lower insulating properties of the surface as well as higher local $\mathrm{pH}$. The near surface $\mathrm{pH}$ was found to be highly alkaline indicating that, even in a buffered solution such as SBF, the local pH on a corroding AZ31 surface can be significantly different to the bulk $\mathrm{pH}$.
\end{abstract}

Keywords: Magnesium (A), electrochemical calculation (B), passive films (C), hydrogen absorption (C), interfaces (C)

\section{Introduction}

Magnesium and its alloys have gained increasing attraction in recent years as biodegradable, biocompatible materials with appropriate mechanical properties [1,2]. However, rapid 
degradation of magnesium in the form of localized corrosion in biological environments is a serious drawback that can significantly reduce the in-vivo service life [3]. For example it has been shown that the stent loses its mechanical integrity and load bearing characteristics much quicker when the corrosion is highly localized in contrast to a uniformly corroding specimen [4]. Therefore, it is crucial to develop techniques to study corrosion profiles in biological systems. Also, despite the advancements in understanding the corrosion behaviour of $\mathrm{Mg}$ and its alloys in simple chloride containing media, there is still essential need for better understanding of corrosion mechanism in physiological environments [5].

Local corrosion behaviour of magnesium alloys has been studied using scanning techniques such as localized EIS [6-8], scanning vibrating electrode technique [9,10] and scanning Kelvin probe [11,12]. Among the methods used to enable local probing of microscopic processes, scanning electrochemical microscopy (SECM) has the unique capability to recognise active/passive regions and allows for surface characterization with a resolution in the micrometre range or below [13]. Electrochemical data may be collected in three main modes; namely amperometric, potentiometric and AC modes. The amperometric and potentiometric modes have been used to study the passive layers [14,15] and organic films [16-19] on metal and defects and pitting [20-22] as well as sensing local $\mathrm{pH}$ on a corroding metal [23]. The more recently introduced AC mode has proven to be useful for studying the insulating/conducting domains as well as changes in electrolyte composition near a corroding metal surface [24-26]. The AC-SECM signal is most responsive to the changes in solution resistance at high frequencies, while at lower frequencies the capacitive/resistive behaviour of the surface and the electrical double layer are the major contributions to the impedance $[24,27]$.

A particular area of interest in recent years has been bio-corrosion and associated electrochemical changes on the surface of Mg alloys in buffered solutions. However, a survey of the literature returns a limited number of published studies on characterizing $\mathrm{Mg}$ alloy surfaces using local probing techniques. Despite the unique capabilities of SECM in this area, it has not thus far been used for studying the corrosion of $\mathrm{Mg}$ in such environments. In this paper SECM is utilized to characterize the local corrosion processes, in real time, on the surface of AZ31 Mg alloy in simulated biological fluid (SBF). The aim of this work is to explore the use of SECM in studying the corrosion of magnesium with an emphasis on its applications in biological systems.

\section{Experimental}

\subsection{Materials and sample preparation}

Simulated biological fluid (SBF) was prepared using analytical grade reagents consisting of $5.403 \mathrm{~g} / \mathrm{l} \mathrm{NaCl}, 0.504 \mathrm{~g} / \mathrm{l} \mathrm{NaHCO}_{3}, 0.426 \mathrm{~g} / \mathrm{l} \mathrm{NaCO}, 0.225 \mathrm{~g} / \mathrm{l} \mathrm{KCl}, 0.230 \mathrm{~g} / \mathrm{l} \mathrm{K} \mathrm{HPO}_{4} \cdot 3 \mathrm{H}_{2} \mathrm{O}$, $0.311 \mathrm{~g} / \mathrm{l} \mathrm{MgCl}_{2} \cdot 6 \mathrm{H}_{2} \mathrm{O}, 0.8 \mathrm{~g} / \mathrm{l} \mathrm{NaOH}, 0.293 \mathrm{~g} / \mathrm{l} \mathrm{CaCl}_{2}, 0.072 \mathrm{~g} / \mathrm{l} \mathrm{Na}_{2} \mathrm{SO}_{4}$ and $17.892 \mathrm{~g} / \mathrm{l}$ HEPES (4-(2-Hydroxyethyl)piperazine-1-ethanesulfonic acid - $\mathrm{C}_{8} \mathrm{H}_{18} \mathrm{~N}_{2} \mathrm{O}_{4} \mathrm{~S}$ ) as buffer agent. The $\mathrm{pH}$ was adjusted to $7.40 \pm 0.05$ using $1 \mathrm{M} \mathrm{NaOH}$ (Sigma) solution. Ferrocenemethanol (FcMeOH) was analytical grade from Sigma. Mg alloy AZ31 (3\% Al, 1\% Zn and 0.3\% Mn, 
all in Wt\%) was supplied by Goodfellow in the form of a sheet $2 \mathrm{~mm}$ thick. Specimens $(5 \mathrm{~mm}$ x 5mm) were abraded using 600, 1200 and 4000 grit emery consecutively and cleaned with isopropanol before exposure to electrolyte.

\subsection{Instrumentation}

Scanning electrochemical microscopy (SECM) was performed using CH Instruments SECM model 920D utilizing CHI integrated software version 12.26. Pt disk ultra-micro-electrodes (UME) $(10 \mu \mathrm{m}$ and $25 \mu \mathrm{m}$ dia), were purchased from $\mathrm{CH}$ Instruments Inc., and were used as working electrodes. Pt mesh and $\mathrm{Ag} / \mathrm{AgCl}(3.0 \mathrm{M} \mathrm{NaCl})$ were used as counter electrode (CE) and reference electrode (RE), respectively. In the manuscript all voltages are stated verses the $\mathrm{Ag} / \mathrm{AgCl}$ reference electrode unless otherwise stated.

\subsection{Experimental procedure}

A SECM image in constant height mode was obtained by scanning the tip in the $x-y$ plane and recording the tip function against tip location. Depending on the operation mode of the SECM, the tip function can be either current (in feedback and generation/collection modes), AC impedance (AC mode) or potential (potentiometry mode). A schematic representation of the SECM set-up used in this study is shown in Figure 1. The distance between tip and substrate was adjusted to $5 \mu \mathrm{m}$ using a digital microscope, (MEIJI Techno model MS50). A working area of $2000 \mu \mathrm{m}$ x $2000 \mu \mathrm{m}$ was examined in each specimen with the remaining surface masked with tape to eliminate interference. All experiments were performed at room temperature, ca. $22{ }^{\circ} \mathrm{C}$, in solution open to air.

\section{Figure 1}

For the surface generated/tip collection (SG/TC) experiments a $10 \mu \mathrm{m}$ diameter Pt UME was used and was biased at a voltage of $0.0 \mathrm{~V}$. When the SECM was used in feedback mode data collection was performed using a ferrocene methanol $(\mathrm{FcMeOH})$ redox mediator at a concentration of $4.0 \mathrm{mM}$ prepared in SBF. The SECM probe was a $10 \mu \mathrm{m}$ diameter Pt UME and biased at $+0.4 \mathrm{~V}$ for oxidation of $\mathrm{FcMeOH}$.

It is necessary to perform alternating current SECM (AC-SECM) in solutions with low ionic strength in order to maximize the sensitivity of the AC response [28]. In this study, SBF was diluted down by a factor of 100 and used for all AC-SECM experiments. All data collection was performed using a $25 \mu \mathrm{m}$ diameter Pt UME. The UME diameter was increased in order 
to improve the signal/noise ratio. Approach curves were collected by moving the Pt UME from a distance of $75 \mu \mathrm{m}$ above the Mg substrate down to $<1 \mu \mathrm{m}$ from the substrate surface. Approach curves were generated at the range of frequency from $75 \mathrm{kHz}$ to $1 \mathrm{kHz}$ in diluted SBF. The UME was held at OCP with an excitation AC signal amplitude of $\pm 100 \mathrm{mV}$.

A solid-state $\mathrm{pH}$ sensing Iridium (Ir) UME was fabricated using a $16 \mu \mathrm{m}$ diameter Ir wire insulated within a glass sheath (Figure 2). The $16 \mu \mathrm{m}$ Ir wire was produced by electrochemical etching a $75 \mu \mathrm{m}$ diameter Ir wire (purchased from e-Filaments, LLC) at +10 $\mathrm{V}$ in $0.5 \mathrm{M} \mathrm{H}_{2} \mathrm{SO}_{4}$ for 20 minutes in a 3 electrode cell utilizing a Pt mesh auxiliary and $\mathrm{Ag} / \mathrm{AgCl}$ reference electrodes. Iridium oxide ( $\mathrm{IrOx}$ ) film was grown on the Ir tip by cycling the potential of the Ir UME between $-0.25 \mathrm{~V}$ and $+1.25 \mathrm{~V}$ at $3000 \mathrm{mV} \mathrm{s}^{-1}$ in $0.5 \mathrm{M} \mathrm{H}_{2} \mathrm{SO}_{4}$ electrolyte for 10000 cycles [29] in a 3-electrode cell utilizing a Pt mesh and Ag/AgCl auxiliary and reference electrode respectively. The Ir/IrOx UME was stored in $0.1 \mathrm{M} \mathrm{NaCl}$ overnight to avoid any influence of initial drift on the measurements [30].

\section{Figure 2}

\section{Results and discussion}

In addition to its high spatial resolution, SECM is best known for its versatility and application in different modes such as feedback mode to differentiate conducting/insulating domains or in generation/collection mode to study interaction with electroactive species on the surface. In this paper the technique is used in feedback, surface generation/tip collection (SG/TC), AC and potentiometry modes to gain information about local corrosion of AZ31 in SBF.

\section{1. $H_{2}$ evolution studied in SG/TC mode}

In SG/TC mode, $\mathrm{H}_{2}$ generation from corrosion of $\mathrm{Mg}$ in neutral or basic solution (reaction 1 [31]) is sensed in an oxidation reaction (reaction 2 and 3) at the UME probe potential of 0.0 V vs. Ag/AgCl.

$$
\begin{aligned}
& \mathrm{Mg}+2 \mathrm{H}_{2} \mathrm{O} \rightarrow \mathrm{Mg}^{2+}+2 \mathrm{OH}^{-}+\mathrm{H}_{2} \\
& \mathrm{H}_{2} \leftrightarrow 2 \mathrm{H}^{+}+2 \mathrm{e} \\
& \mathrm{H}_{2}+2 \mathrm{OH}^{-} \rightarrow 2 \mathrm{H}_{2} \mathrm{O}+2 \mathrm{e}
\end{aligned}
$$

At higher $\mathrm{pH}$ values reaction 3 will dominate the hydrogen consumption at the UME. The potential at which reactions 2 and 3 take place is $\mathrm{pH}$ dependent as given by equation 4 (for $\mathrm{H}_{2}$ at $1 \mathrm{~atm}$ pressure): 


$$
\mathrm{e}_{\mathrm{H}^{+} / \mathrm{H}_{2}}=-0.059 \mathrm{pH}
$$

At $\mathrm{pH}$ as high as 8.5 , in close proximity to the $\mathrm{Mg}$ surface, the reduction potential of the hydrogen is $-0.5 \mathrm{~V}$ vs SHE ( $-0.7 \mathrm{~V}$ vs $\mathrm{Ag} / \mathrm{AgCl}$ ). Therefore, potentials more positive than $0.5 \mathrm{~V}$ SHE could theoretically be set as the UME tip potential to sense the generation of $\mathrm{H}_{2}$. The schematic in Figure 3 represents the principle of sensing $\mathrm{H}_{2}$ at the UME biased at such potential.

\section{Figure 3}

Using the $10 \mu \mathrm{m}$ UME cyclic voltammograms were recorded in SBF (Figure 4) with and without the presence of a Mg sample. The CV recorded with the UME positioned $8 \mu \mathrm{m}$ from the Mg surface exhibited a peak oxidation current centred at $-0.3 \mathrm{~V}$ which is attributed to the oxidation of the hydrogen $\left(\mathrm{H}_{2}\right)$ generated at the $\mathrm{Mg}$ surface due to corrosion (reaction 1 ). No oxidation peak is observed in this region when a CV is recorded using the UME in SBF only (no Mg sample present - SBF background) confirming that the peak recorded with the Mg sample present is due to $\mathrm{H}_{2}$ oxidation. Also it is observed that the current was significantly reduced when the UME is positioned at long $(2000 \mu \mathrm{m})$ distances from the Mg substrate. This decrease is due to the lower concentration of generated $\mathrm{H}_{2}$ at long distances from the substrate surface.

\section{Figure 4}

The CV of UME in fresh SBF (Figure 4 - SBF background) shows a significant increase of negative (reduction) current at potentials more negative than $-0.1 \mathrm{~V}$ which is related to reduction of dissolved $\mathrm{O}_{2}$ in the SBF. Under standard conditions, at potentials negative of $0.2 \mathrm{~V}$ the reduction of $\mathrm{O}_{2}\left(\mathrm{O}_{2}+2 \mathrm{H}_{2} \mathrm{O}+4 e^{-} \leftrightarrow 4 \mathrm{OH}^{-}\right)$occurs in solution open to air [32]. Mapping the $\mathrm{O}_{2}$ has been used previously in corrosion studies of metals [32,33], however it is known that $\mathrm{O}_{2}$ plays a minor role in corrosion of magnesium [31] and therefore should not be considered in SG/TC mode for studying Mg corrosion. In order to avoid any potential interference from $\mathrm{O}_{2}$ reduction, a UME potential more negative than $-0.1 \mathrm{~V}$ was not considered in this work. Although the CVs recorded in the presence of $\mathrm{Mg}$ specimen (Figure 4) does not show negative (reduction) current in the range of $-0.1 \mathrm{~V}$ to $-0.7 \mathrm{~V}$, it is thought that the $\mathrm{O}_{2}$ reduction current is masked by the strong positive oxidation current of $\mathrm{H}_{2}$. Therefore, in order to eliminate any contribution of dissolved $\mathrm{O}_{2}$ to the tip current, a potential range of -0.1 to $+0.2 \mathrm{~V}$ was considered appropriate for mapping the $\mathrm{H}_{2}$ evolution (solid box in Figure 4). At potentials more positive of $+0.2 \mathrm{~V}$ the current generated from the oxidation of generated $\mathrm{H}_{2}$ decreases sharply. Further investigation showed good resolution and sensitivity towards $\mathrm{H}_{2}$ oxidation at the UME probe positioned close to the Mg surface when the UME 
was biased at $0.0 \mathrm{~V}$ and therefore the SECM experiments in SG/TC mode were performed at this potential.

Hydrogen collection is one of the most trusted methods of measuring the corrosion rate of magnesium and its alloys in aqueous media [34,35]. The technique produces quantitative values of corrosion rate based on cumulative hydrogen evolved due to the corrosion of magnesium (see reaction 1). Using SECM in SG/TC mode presents an alternative way of studying the corrosion rate employing a local approach. Due to the complexity of $\mathrm{Mg}$ corrosion mechanism, bulk electrochemical techniques, such as potentiodynamic polarisation, have been found to produce erroneous results in many cases by not taking into account the chemical dissolution of $\mathrm{Mg}$ [36]. The SG/TC mode of SECM allows for instantaneous measurement of the $\mathrm{H}_{2}$ evolution as a direct measure of corrosion rate and has a great potential as a qualitative method for comparative studies. There has also been ongoing debates in the literature over the source of hydrogen evolution during the corrosion of magnesium [37-40]. It is believed that the SG/TC mode of SECM for probing $\mathrm{H}_{2}$ evolution introduces new possibilities to gain better insights into the degradation mechanism of magnesium.

\subsection{Conducting/insulating domains studied in feedback mode}

Data collection in feedback mode involves the use of a redox mediator that changes its oxidation state in contact with the appropriately biased UME tip and substrate. In the vicinity of a suitably biased conductive or electrochemically active surface, the mediator returns to the original oxidation state resulting in higher concentration of detectable mediator species at the UME tip and higher feedback current. This effect is called the "positive feedback" effect. Conversely, in the vicinity of an insulating surface, the diffusion of mediator from the bulk solution is hindered by the insulating material on the substrate around the UME tip, resulting in a decrease in feedback current. This effect is called "negative feedback" effect. Figure 5 illustrates the principle of positive feedback effect using ferrocenemethanol (FcMeOH) as the redox mediator in contact with the Mg surface.

\section{Figure 5}

In the bulk solution, because of the small dimension of the microelectrode, mass transfer is controlled solely by hemispherical diffusion of the redox mediator towards the UME tip. At a set distance sufficiently far from the Mg surface (i.e., in the bulk solution) the steady-state current measured at the UME $\left(I_{\infty}\right)$, is proportional to bulk concentration of redox mediator $\left(C^{\infty}\right)$, diffusion coefficient of the redox mediator $(D)$, and number of electrons involved in the redox reaction, $(n)$, according to equation 5 [41] where $a$ is the UME radius and $F$ is the Faraday constant. 


$$
I_{\infty}=4 n F D C^{\infty} a
$$

The redox mediator, in order to be effective for SECM feedback mode imaging, must have fast redox kinetics and display minimal interaction with the active substances on the $\mathrm{Mg}$ surface to minimize interference of the corrosion processes. In studying the corrosion of $\mathrm{Mg}$, it is important to make sure that the redox kinetics of the mediator is not influenced by the high $\mathrm{pH}$ and $\mathrm{Mg}^{2+}$ dissolution in close vicinity of the surface. In the feedback mode imaging of Mg corrosion, it is also crucial to avoid using UME bias potentials at which $\mathrm{H}_{2}$ is oxidized. These conditions will ensure that only the feedback current produced by the mediator is recorded. A dashed box in Figure 4 identifies the potential window at which the redox mediator $(\mathrm{FcMeOH})$ is oxidized at the UME with no interference from $\mathrm{H}_{2}$ evolution (region designated by the solid line box in Figure 4). There was no change in the bulk steady-state current $\left(I_{\infty}\right)$ recorded in solutions of SBF containing $4 \mathrm{mM} \mathrm{FcMeOH}$ at various $\mathrm{pH}$ (adjusted using $\mathrm{NaOH}$ ) and $\mathrm{Mg}^{2+}$ concentrations (adjusted using $\mathrm{MgCl}_{2}$ ) indicating that this mediator is not influenced by changing $\mathrm{pH}$ or $\mathrm{Mg}^{2+}$ concentration. Ferrocene undergoes a one-electron oxidation at potentials positive to $+0.2 \mathrm{~V}$, as shown by the positive current in Figure 4 . This reversible reaction serves as an electron transfer mediator for collecting the feedback mode data on the $\mathrm{Mg}$ surface. In order to eliminate interference from $\mathrm{H}_{2}$ oxidation, potentials more positive than $+0.4 \mathrm{~V}$ were used for feedback imaging.

Figures $6 \mathrm{a}$ and $6 \mathrm{~b}$ show the $\mathrm{H}_{2}$ map and conducting/insulating domains on the surface of the same AZ31 sample after $1 \mathrm{hr}$ immersion in SBF acquired using SG/TC and feedback modes, respectively. The upper scale colours (magenta and blue) on Figure 6a indicate the areas with high $\mathrm{H}_{2}$ evolution rate whereas the lower scale colours (red and yellow) represent the relatively passive areas with low $\mathrm{H}_{2}$ evolution. In Figure 6b, the upper scale colours indicate the areas with higher feedback current (i.e., higher conductivity regions) versus the lower scale colours that represent areas with lower feedback current (i.e., lower conductive regions). These lower conductive regions are most likely due to the formation of an insulating surface layer. Comparing Figures $6 a$ and $6 b$, relatively higher activity/conductivity is observed at (but not limited to) the main domains of high $\mathrm{H}_{2}$ evolution. This result is consistent with the micro-galvanic corrosion mechanism in buffered media [42] and chloride containing solutions [35] caused by intermetallic particles. It has been shown that intermetallic particles and secondary phases, when isolated, may increase the corrosion rate of $\mathrm{Mg}$ by forming micro-galvanic corrosion cells [43,44].

\section{Figure 6}

In the context of corrosion of Mg, the feedback mode of SECM can be particularly useful in obtaining information about the formation and breakdown of passive surface layers. It is well 
known that corrosion inhibition of Mg alloys to a large extent depends on the formation and stability of the formed passive layer. Here it is postulated that the local formation of a surface layer when immersed in SBF slows down the corrosion rate and therefore reduces the generation of $\mathrm{H}_{2}$.

\subsection{Capacitive/resistive characteristics studied in AC mode}

AC-SECM imaging comprises of recording impedance (imaginary and real) and phase shift via counter electrode (CE) as a response to the AC signal applied at the UME at a set frequency and excitation amplitude. Figure 7 illustrates the electrical model for SECM data acquisition in AC mode at conducting and insulating domains of the Mg surface [45].

\section{Figure 7}

Prior to performing AC-SECM in diluted SBF each Mg sample was immersed in standard SBF (undiluted) solution for $1 \mathrm{hr}$. Approach curves were obtained by moving the UME towards the Mg surface whilst holding the UME at its open circuit potential and measuring the resulting impedance. An AC potential $( \pm 100 \mathrm{mV})$ was applied onto the OCP and each approach curves were obtained at a set frequency to determine the response of the surface film as a function of the frequency (Figure 8). Normalized impedance was calculated using equation 6;

normalized impedance $={ }^{Z_{L}} /_{Z_{\infty}}$

where $Z_{L}$ is the impedance at distance $L$ from the substrate and $Z_{\infty}$ is the bulk impedance at $75 \mu \mathrm{m}$ distance from the $\mathrm{Mg}$ substrate. Normalized tip-substrate distance was calculated as;

normalized tip - substrate distance $=L / D$

where $L$ is the actual tip-substrate distance in $\mu \mathrm{m}$ and $\mathrm{D}$ is the tip diameter.

Figure 8 shows the normalised approach curves in which a positive feedback (i.e., increasing normalised AC impedance as the UME approaches the Mg surface) was observed at lower frequencies ( $\mathrm{f} \leq 15 \mathrm{kHz}$ ) and negative feedback (i.e., decreasing normalised AC impedance as the UME approaches the Mg surface) was observed at higher frequencies ( $>42 \mathrm{kHz}$ ). In general, a positive feedback effect is observed when the frequency of the applied AC signal to the UME is smaller than the reciprocal of the time constant for the interfacial impedance ( $\mathrm{f}$ $<1 / 2 \pi R C$ ), whereas negative feedback is observed for higher frequencies [26]. As a surface film grows on the bare $\mathrm{Mg}$ surface, the time constant associated with the surface film 
increases, resulting in a lower frequency at which the switch from positive to negative feedback occurs [26]. Thus, the frequency at which a distinct variation between bare Mg surface and Mg surface covered with a film is observed will decrease. Approach curves shown in Figure 8 suggest that adequate sensitivity of AC signal to insulating properties of the $\mathrm{Mg}$ surface layer is obtained at low frequencies, namely $1 \mathrm{kHz}$.

\section{Figure 8}

As indicated by the approach curves (Figure 8), good resolution with high sensitivity towards the surface layer was observed at $1 \mathrm{kHz}$ with $100 \mathrm{mV}$ amplitude of excitation voltage. A similar frequency has been used elsewhere for imaging pitting corrosion [46,47]. Figure 9a shows the impedance map from AC-SECM taken from the same area that was scanned in SG/TC and feedback modes (Figure 6a and 6b respectively). Upper scale colours in Figure 9a (magenta and blue) represent the relatively low conductivity areas versus lower scale colours (red and yellow) that indicate the more conductive areas. Figure 9b shows the optical micrograph of the sample after the AC-SCEM experiment. It is notable, by comparing Figure 9a and Figure 6a, that the surface layer is significantly more conducting at most sites of active $\mathrm{H}_{2}$ evolution. Furthermore, from Figure 9a we observe that very low conductive domains exist in close proximity to some active $\mathrm{H}_{2}$ evolution sites.

\section{Figure 9}

The increase of conductivity at the domains of higher $\mathrm{H}_{2}$ evolution (comparing Figures 9a and 6a) could be attributed to the increase of ionic strength within the gap between the sample and the UME due to dissolved $\mathrm{Mg}^{2+}$ metal ions and/or the removal of the surface film from the Mg sample thus exposing the underlying metal. The porosity of the surface film results in a positive AC-feedback effect at both corroding and covered areas [26]. These domains are distinguishable by their difference in the strength of positive feedback signal indicating that even the areas covered by a resistive surface film are not perfectly insulated (i.e. the surface film is porous) allowing the AC signal to pass through.

When the AC mode results are combined with SG/TC mode data, it reveals that the Mg is not covered by a surface film in the domains of high $\mathrm{H}_{2}$ evolution where anodic dissolution of Mg takes place [48]. The feedback mode results identified these areas with increased activity and enhanced electron transfer properties. This suggests that anodic dissolution of $\mathrm{Mg}$ is either accompanied by $\mathrm{H}_{2}$ evolution or it takes place at very close vicinity to isolated cathodic areas, presumably Al-Mg intermetallics. Preferential anodic dissolution of $\mathrm{Mg}$ against $\mathrm{Al}-\mathrm{Mg}$ intermetallics has been shown elsewhere [49]. 
Here the AC mode of SECM is shown to be a useful method for studying resistive properties of the surface layer that forms on the surface of Mg during corrosion. While the low, $1 \mathrm{kHz}$, frequency scan distinguish between domains of lower conductivity and those of higher conductivity, more information about capacitive properties of the surface layer at a certain area may be achieved through AC approach curves (Figure 8) over a range of frequencies. The main advantage of the AC mode over the other feedback modes is the elimination of the redox mediator that in some cases may interfere with the natural corrosion process or may react with active/passive domains on the surface. Although not attempted here, AC mode SECM has shown potential for studying the surface profile in-situ at high frequency ranges $[27,50]$.

\section{4. $\mathrm{pH}$ sensing in Potentiometric mode}

Potentiometric mode is a two electrode configuration of SECM in which the open circuit potential of UME tip is measured against the reference electrode as a function of tip location and can be used to map the $\mathrm{pH}$ near the surface of a sample surface. In order to do this a calibration curve of OCP verses solution $\mathrm{pH}$ must be prepared. Therefore, SBF solutions of varying $\mathrm{pH}$ were prepared using fresh PBS and $0.1 \mathrm{M} \mathrm{HCl}$ and $0.1 \mathrm{M} \mathrm{NaOH}$. These solutions were used to generate a calibration curve (Figure 10a). A similar method was used to sense $\mathrm{pH}$ on Al-Zn in un-buffered media by Lowe et al [30]. The possible interference of $\mathrm{H}_{2}$ was ruled out by measuring OCP in SBF solutions with and without dissolved $\mathrm{H}_{2}$, (from a corroding Mg sample) without any variation in OCP (at a fixed $\mathrm{pH}$ ) observed.

\section{Figure 10}

In order to measure local $\mathrm{pH}$ (Figure $10 \mathrm{~b}$ ), a $\mathrm{H}_{2}$ map was first collected using the SG/TC mode (Section 3.1). The $\mathrm{H}_{2}$ map was then used as a guide to find the domains with different levels of $\mathrm{H}_{2}$ evolution. The $\mathrm{Ir} / \mathrm{IrOx} \mathrm{UME}$ was then moved precisely above the points of interest and OCP was measured against $\mathrm{Ag} / \mathrm{AgCl}$ at approximately $30 \mu \mathrm{m}$ distance from the $\mathrm{Mg}$ surface. The calibration curve (Figure 10a) was used to convert the OCP values to $\mathrm{pH}$. The $\mathrm{pH}$ of bulk buffered solution was measured and remained at 7.6 during these experiments. As illustrated in Figure 10b, the near surface $\mathrm{pH}$ is significantly higher than that of bulk; with local $\mathrm{pH}$ at some sites of $\mathrm{H}_{2}$ evolution reaching as high as 11.9.

The near surface $\mathrm{pH}$ plays an essential role in determining the formation and stability of the surface layer on Mg. It is well known that most magnesium hydroxide and calcium phosphate layers that form on the surface of $\mathrm{Mg}$ are stable at high $\mathrm{pH}$ and tend to break down at low or neutral $\mathrm{pH}[5,51]$. It is believed that near surface $\mathrm{pH}$ measured by $\mathrm{Ir} / \mathrm{IrOx} \mathrm{UME}$ in this study can provide valuable information that helps better understand the formation of a surface layer of $\mathrm{Mg}$ alloys in physiological media. 


\section{Conclusion}

Four modes of SECM operation (i.e. SG/TC, feedback, AC and potentiometry) were used for in-situ characterisation of $\mathrm{Mg}$ surface corrosion in a biological buffered solution. Combining the variables measured in different modes of SECM provides new insight into the complex corrosion mechanism of $\mathrm{Mg}$ in a buffered media. The $\mathrm{H}_{2}$ probing performed using SG/TC provides a direct measure of the spontaneous corrosion rate on a local scale. $\mathrm{H}_{2}$ evolution is sensed in an electro-oxidation reaction at the SECM probe producing a current that increases by increasing local concentration of $\mathrm{H}_{2}$. Using the feedback mode it was found that the $\mathrm{Mg}$ surface is more active (in the context of electron transfer) at the domains of high $\mathrm{H}_{2}$ evolution. The AC mode of SECM shows promise in probing the areas that are covered with an insulating surface film, with high sensitivity at low AC frequencies. Complementary to the SG/TC and feedback modes, the AC mode results revealed that Mg is not covered by a surface film in the domains of high $\mathrm{H}_{2}$ evolution where hypothetically anodic dissolution of Mg takes place. This implies that anodic dissolution of Mg either coincides with $\mathrm{H}_{2}$ evolution or it takes place at very close proximity to isolated cathodic areas and is also in-line with the highly alkaline $\mathrm{pH}$ at these domains. The near surface $\mathrm{pH}$ was found to be alkaline despite the SBF bulk solution being buffered to 7.4. This has significant impact on the mechanisms involved in formation of surface passive layer as well as the cytocompatibility of magnesium. The regions of highest $\mathrm{pH}$ correlated with the major domains of $\mathrm{H}_{2}$ evolution and lower surface resistivity.

\section{Acknowledgments}

The authors thank the Australian Research Council (ARC) for continuing financial support. GGW and MF thank the ARC for their Laureate Fellowships and SEM thanks the ARC for his QEII Fellowship. SSJ would like to thank Prof. R.M. Souto and Prof. W. Schuhmann for their valuable suggestions. The authors also thank Dr Chee O Too for his valued contribution in editing this manuscript.

\section{References}

[1] R. Erbel, C. Di Mario, J. Bartunek, J. Bonnier, B. de Bruyne, F.R. Eberli, et al., Temporary scaffolding of coronary arteries with bioabsorbable magnesium stents: a prospective, non-randomised multicentre trial., Lancet. 369 (2007) 1869-75.

[2] G. Zhang, J. Huang, K. Yang, B. Zhang, H. Ai, Experimental study of in vivo implantation of a magnesium alloy at early stage, Acta. Metall. Sin. 43 (2007) 11861190.

[3] S. Virtanen, Biodegradable Mg and Mg alloys: Corrosion and biocompatibility, Mater Sci Eng B. 176 (2011) 1600-1608. 
[4] J.A. Grogan, B.J. O’Brien, S.B. Leen, P.E. McHugh, A corrosion model for bioabsorbable metallic stents., Acta Biomater. 7 (2011) 3523-33.

[5] A. Atrens, M. Liu, N.I. Zainal Abidin, Corrosion mechanism applicable to biodegradable magnesium implants, Mater Sci Eng B. 176 (2011) 1609-1636.

[6] G. Baril, C. Blanc, M. Keddam, N. Pébère, Local Electrochemical Impedance Spectroscopy Applied to the Corrosion Behavior of an AZ91 Magnesium Alloy, J. Electrochem. Soc. 150 (2003) B488.

[7] G. Galicia, N. Pébère, B. Tribollet, V. Vivier, Local and global electrochemical impedances applied to the corrosion behaviour of an AZ91 magnesium alloy, Corros. Sci. 51 (2009) 1789-1794.

[8] V. Barranco, N. Carmona, J.J.C. Galván, M. Grobelny, L. Kwiatkowski, M. a. M. Villegas, Electrochemical study of tailored sol-gel thin films as pre-treatment prior to organic coating for AZ91 magnesium alloy, Prog. Org. Coat. 68 (2010) 347-355.

[9] M.F. Montemor, M.G.S. Ferreira, Analytical characterisation and corrosion behaviour of bis-aminosilane coatings modified with carbon nanotubes activated with rare-earth salts applied on AZ31 Magnesium alloy, Surf. Coat. Technol. 202 (2008) 4766-4774.

[10] G. Williams, H.N. McMurray, Localized Corrosion of Magnesium in ChlorideContaining Electrolyte Studied by a Scanning Vibrating Electrode Technique, J. Electrochem. Soc. 155 (2008) C340.

[11] E. Juzeliūnas, A. Sudavičius, K. Juttner, W. Furbeth, Study of initial stages of Al-Mg alloy corrosion in water, chloride and $\mathrm{Cu}$ (II) environment by a scanning Kelvin probe and XPS, Electrochem. Commun. 5 (2003) 154-158.

[12] M. Jönsson, D. Thierry, N. LeBozec, The influence of microstructure on the corrosion behaviour of AZ91D studied by scanning Kelvin probe force microscopy and scanning Kelvin probe, Corros. Sci. 48 (2006) 1193-1208.

[13] M.B. Jensen, D.E. Tallman, Application of SECM in corrosion reseach, in: A.J. Bard, M.V. Mirkin (Eds.), Scanning Electrochemical Microscopy, 2nd editio, Taylor and Francis/CRC Press, NY, USA, 2012: pp. 451-488.

[14] J.W. Stills, D. Wipf, Breakdown of the Iron Passive Layer by Use of the Scanning Electrochemical Microscope, J. Electrochem. Soc. 144 (1997) 2657-2665.

[15] J. Izquierdo, J. Santana, S. González, R.M. Souto, Uses of scanning electrochemical microscopy for the characterization of thin inhibitor films on reactive metals: The protection of copper surfaces by benzotriazole, Electrochim. Acta. 55 (2010) 87918800.

[16] R.M. Souto, Y. González-garcía, J. Izquierdo, S. González, Examination of organic coatings on metallic substrates by scanning electrochemical microscopy in feedback mode : Revealing the early stages of coating breakdown in corrosive environments, Corros. Sci. 52 (2010) 748-753. 
[17] Y. Shao, C. Jia, G. Meng, T. Zhang, F. Wang, The role of a zinc phosphate pigment in the corrosion of scratched epoxy-coated steel, Corros. Sci. 51 (2009) 371-379.

[18] R.M. Souto, Y. González-García, S. González, G.T. Burstein, Damage to paint coatings caused by electrolyte immersion as observed in situ by scanning electrochemical microscopy, Corros. Sci. 46 (2004) 2621-2628.

[19] R.M. Souto, Y. González-García, S. González, Evaluation of the corrosion performance of coil-coated steel sheet as studied by scanning electrochemical microscopy, Corros. Sci. 50 (2008) 1637-1643.

[20] L. Niu, Y. Yin, W. Guo, M. Lu, R. Qin, S. Chen, Application of scanning electrochemical microscope in the study of corrosion of metals, J. Mater. Sci. 44 (2009) 4511-4521.

[21] C. Li, L. Li, C. Wang, Y. Zhu, W. Zhang, Study of the protection performance of selfassembled monolayers on copper with the scanning electrochemical microscope, Corros. Sci. 80 (2014) 511-516.

[22] X. Liu, T. Zhang, Y. Shao, G. Meng, F. Wang, Effect of alternating voltage treatment on the corrosion resistance of pure magnesium, Corros. Sci. 51 (2009) 1772-1779.

[23] J. Izquierdo, L. Nagy, Á. Varga, J.J. Santana, G. Nagy, R.M. Souto, Spatially resolved measurement of electrochemical activity and $\mathrm{pH}$ distributions in corrosion processes by scanning electrochemical microscopy using antimony microelectrode tips, Electrochim. Acta. 56 (2011) 8846-8850.

[24] B. Ballesteros, A. Schulte, E.J. Calvo, M. Koudelka-hep, W. Schuhmann, Localised electrochemical impedance spectroscopy with high lateral resolution by means of alternating current scanning electrochemical microscopy, Electrochem. Commun. 4 (2002) 134-138.

[25] M. Pähler, J.J.J. Santana, W. Schuhmann, R.M. Souto, Application of AC-SECM in corrosion science: local visualisation of inhibitor films on active metals for corrosion protection., Chem. Eur. J. 17 (2011) 905-11.

[26] G. Baril, G. Galicia, C. Deslouis, N. Pébère, B. Tribollet, V. Vivier, An Impedance Investigation of the Mechanism of Pure Magnesium Corrosion in Sodium Sulfate Solutions, J. Electrochem. Soc. 154 (2007) C108.

[27] K. Eckhard, W. Schuhmann, Alternating current techniques in scanning electrochemical microscopy (AC-SECM), Analyst. 133 (2008) 1486-97.

[28] M. Etienne, A. Schulte, W. Schuhmann, High resolution constant-distance mode alternating current scanning electrochemical microscopy (AC-SECM), Electrochem. Commun. 6 (2004) 288-293.

[29] M.L. Hitchman, S. Ramanathan, Considerations of the $\mathrm{pH}$-dependence of hydrous oxide-films formed on iridium by voltammetric cycling, Electroanalysis. 4 (1992) 29197. 
[30] T. a. Lowe, G.G. Wallace, A.K. Neufeld, Insights into the cut edge corrosion of 55\% $\mathrm{Al}-\mathrm{Zn}$ metal coating on steel from simultaneous electrochemical polarization and localised pH sensing experiments, Corros. Sci. 55 (2012) 180-186.

[31] G.-L. Song, Corrosion electrochemistry of magnesium (Mg) and its alloys, in: G.-L. Song (Ed.), Corrosion of Magnesium Alloys, Woodhead Publishing Ltd, Cambridge, UK, 2011: p. 38.

[32] R.M. Souto, Y. González-García, S. González, In situ monitoring of electroactive species by using the scanning electrochemical microscope. Application to the investigation of degradation processes at defective coated metals, Corros. Sci. 47 (2005) 3312-3323.

[33] R.M. Souto, L. Fernandez-Marida, S. Gonzalez, SECM Imaging of Interfacial Processes in Defective Organic Coatings Applied on Metallic Substrates Using Oxygen as Redox Mediator, Electroanalysis. 21 (2009) 2640-2646.

[34] G. Song, A. Atrens, D.S. John, An hydrogen evolution method for the estimation of the corrosion rate of magnesium alloys, in: Magnesium Technology 2001 Symposium, Minerals, Metals \& Materials Society, New Orleans, LA, 2001: pp. 255-262.

[35] F. Cao, Z. Shi, G.-L. Song, M. Liu, A. Atrens, Corrosion behaviour in salt spray and in $3.5 \% \mathrm{NaCl}$ solution saturated with $\mathrm{Mg}(\mathrm{OH}) 2$ of as-cast and solution heat-treated binary Mg-X alloys: X=Mn, Sn, Ca, Zn, Al, Zr, Si, Sr, Corros. Sci. 76 (2013) 60-97.

[36] F. Cao, Z. Shi, J. Hofstetter, P.J. Uggowitzer, G. Song, M. Liu, et al., Corrosion of ultra-high-purity $\mathrm{Mg}$ in 3.5\% $\mathrm{NaCl}$ solution saturated with $\mathrm{Mg}(\mathrm{OH}) 2$, Corros. Sci. 75 (2013) 78-99.

[37] G. Song, A. Atrens, D. John, X. Wu, J. Nairn, The anodic dissolution of magnesium in chloride and sulphate solutions, Corros. Sci. 39 (1997) 1981-2004.

[38] Y. Song, D. Shan, R. Chen, F. Zhang, E.-H. Han, Biodegradable behaviors of AZ31 magnesium alloy in simulated body fluid, Mater Sci Eng C. 29 (2009) 1039-1045.

[39] J. Chen, J. Wang, E. Han, J. Dong, W. Ke, AC impedance spectroscopy study of the corrosion behavior of an AZ91 magnesium alloy in 0.1 M sodium sulfate solution, Electrochim. Acta. 52 (2007) 3299-3309.

[40] G.S. Frankel, A. Samaniego, N. Birbilis, Evolution of hydrogen at dissolving magnesium surfaces, Corros. Sci. 70 (2013) 104-111.

[41] M.V. Mirkin, Theory, in: A.J. Bard, M.V. Mirkin (Eds.), Scanning Electrochemical Microscopy, 1st edition, Marcel Dekker Inc, New York, NY, 2001: pp. 145-199.

[42] N.I. Zainal Abidin, B. Rolfe, H. Owen, J. Malisano, D. Martin, J. Hofstetter, et al., The in vivo and in vitro corrosion of high-purity magnesium and magnesium alloys WZ21 and AZ91, Corros. Sci. 75 (2013) 354-366. 
[43] M.C. Zhao, M. Liu, G. Song, A. Atrens, Influence of the $\beta$-phase morphology on the corrosion of the Mg alloy AZ91, Corros. Sci. 50 (2008) 1939-1953.

[44] G.-L.G. Song, A. Atrens, Corrosion mechanisms of magnesium alloys, Adv. Eng. Mater. 1 (1999) 11-33.

[45] K. Eckhard, T. Erichsen, M. Stratmann, W. Schuhmann, Frequency-dependent alternating-current scanning electrochemical microscopy (4D AC-SECM) for local visualisation of corrosion sites., Chem. Eur. J. 14 (2008) 3968-76.

[46] A. Schulte, S. Belger, M. Etienne, W. Schuhmann, Imaging localised corrosion of NiTi shape memory alloys by means of alternating current scanning electrochemical microscopy (AC-SECM), Mater. Sci. Eng., A. 378 (2004) 523-526.

[47] D. Ruhlig, H. Gugel, A. Schulte, W. Theisen, W. Schuhmann, Visualization of local electrochemical activity and local nickel ion release on laser-welded NiTi/steel joints using combined alternating current mode and stripping mode SECM., Analyst. 133 (2008) 1700-6.

[48] A. Atrens, G.-ling Song, F. Cao, Z. Shi, P.K. Bowen, Advances in Mg corrosion and research suggestions, J Magnesium Alloys. 1 (2013) 177-200.

[49] M. Liu, S. Zanna, H. Ardelean, I. Frateur, P. Schmutz, G. Song, et al., A first quantitative XPS study of the surface films formed, by exposure to water, on Mg and on the Mg-Al intermetallics: Al3Mg2 and Mg17Al12, Corros. Sci. 51 (2009) 11151127.

[50] J. Izquierdo, S. González, R.M. Souto, Application of AC-SECM in Corrosion Science: Local Visualization of Heterogeneous Chemical Activity in AA2024 Surfaces, Int. J. Electrochem. Sci. 7 (2012) 11377-11388.

[51] G. Song, A. Atrens, Understanding magnesium corrosion - a framework for improved alloy performance, Adv. Eng. Mater. 5 (2003) 837-858. 


\section{Figure captions}

Figure 1 Schematic representation of SECM set-up with Mg sample (mounted in epoxy) as substrate and Pt UME as working electrode (WE). In this study Pt mesh was used as counter electrode (CE) and $\mathrm{Ag} / \mathrm{AgCl}$ was used as reference electrode (RE).

Figure 2 Optical micrographs of the Ir UME fabricated by etching the Ir wire and insulation in glass sheath.

Figure 3 Schematic principle of $\mathrm{H}_{2}$ probing in SG/TC mode of SECM using a polarized Pt UME to oxidize $\mathrm{H}_{2}$ over the corroding surface of $\mathrm{Mg}$.

Figure 4 Cyclic voltammograms of a $10 \mu \mathrm{m}$ Pt UME in SBF showing the redox behaviour of the redox mediator $\mathrm{FcMeOH}$ compared with the probe current generated by $\mathrm{H}_{2}$ oxidation. Solid line box represents the potential window in which $\mathrm{H}_{2}$ evolution can be measured using SG/TC mode whilst the dash box represents the potential window in which the FcMeOH redox mediator can be detected in feedback mode. SBF background was obtained with fresh SBF and no Mg present in the solution. The concentration of FcMeOH in SBF was 4.0 mM.

Figure 5 Schematic representation of SECM probe in feedback mode of operation showing redox activity of ferrocenemethanol $(\mathrm{FcMeOH})$ in contact with $\mathrm{Mg}$ substrate and cathodically biased Pt UME.

Figure 6 SECM images of AZ31 surface in SG/TC (a) and feedback (b) modes acquired via sensing the $\mathrm{H}_{2}$ evolution and $\mathrm{FcMeOH}(4 \mathrm{mM})$ regeneration. The tip potential in feedback mode was $0.55 \mathrm{~V}$ (vs. $\mathrm{Ag} / \mathrm{AgCl}$ ) and in SG/TC mode was $0.0 \mathrm{~V}$ (vs. Ag/AgCl). Both images were acquired on AZ31 surface after $1 \mathrm{hr}$ immersion in SBF with 10 $\mathrm{\mu m}$ Pt UME.

Figure 7 Schematic of the electrical model of AC mode data acquisition at conducting and insulating regions of an $\mathrm{Mg}$ surface.

Figure 8 Normalized approach curves at the range of frequency from $75 \mathrm{kHz}$ to $1 \mathrm{kHz}$ towards the surface of AZ31 in diluted SBF. AZ31 was at open circuit potential. The probe was a $25 \mu \mathrm{m}$ diameter Pt UME held at OCP with excitation signal amplitude of $\pm 100 \mathrm{mV}$.

Figure 9 AC-SECM image (a) and optical micrograph (b) of AZ31 after $1 \mathrm{hr}$ immersion in SBF. AC mode experiments were performed in diluted SBF using a $25 \mu \mathrm{m}$ Pt UME with excitation signal amplitude of $100 \mathrm{mV}$ at $1 \mathrm{kHz}$.

Figure 10 Calibration curve correlating $\mathrm{Ir} / \mathrm{IrOx}$ potential to the $\mathrm{pH}$ of solution (a) and the local (single point) $\mathrm{pH}$ values shown on a $\mathrm{H}_{2}$ map (b). Ir/IrOx UME was positioned precisely above the points of interest and OCP potential was recorded against $\mathrm{Ag} / \mathrm{AgCl}$. Individual $\mathrm{pH}$ values were converted from OCP values using the calibration graph. 


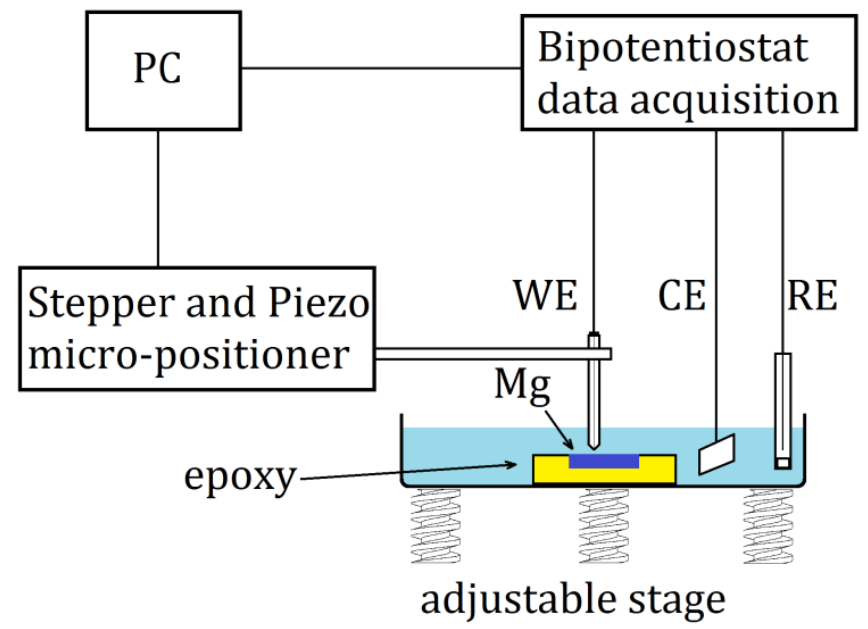

Figure 1 Schematic representation of SECM set-up with Mg sample (mounted in epoxy) as substrate and Pt UME as working electrode (WE). In this study Pt mesh was used as counter electrode (CE) and Ag/AgCl was used as reference electrode (RE).
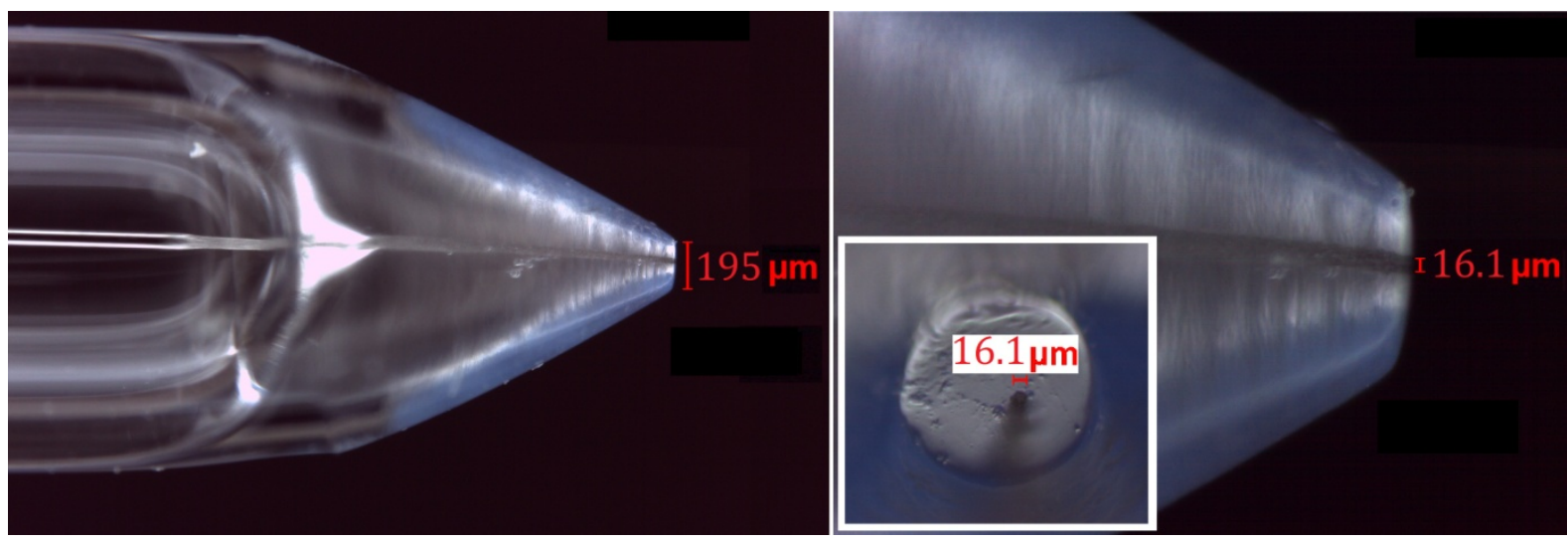

Figure 2 Optical micrographs of the Ir UME fabricated by etching the Ir wire and insulation in glass sheath. 


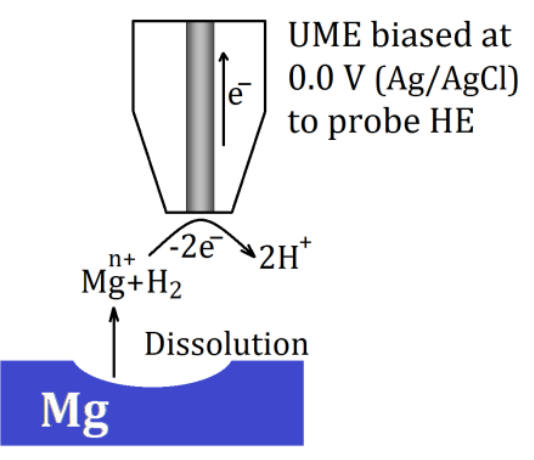

Figure 3 Schematic principle of $\mathrm{H}_{2}$ probing in SG/TC mode of SECM using a polarized $\mathrm{Pt}$ $\mathrm{UME}$ to oxidize $\mathrm{H}_{2}$ over the corroding surface of $\mathrm{Mg}$.

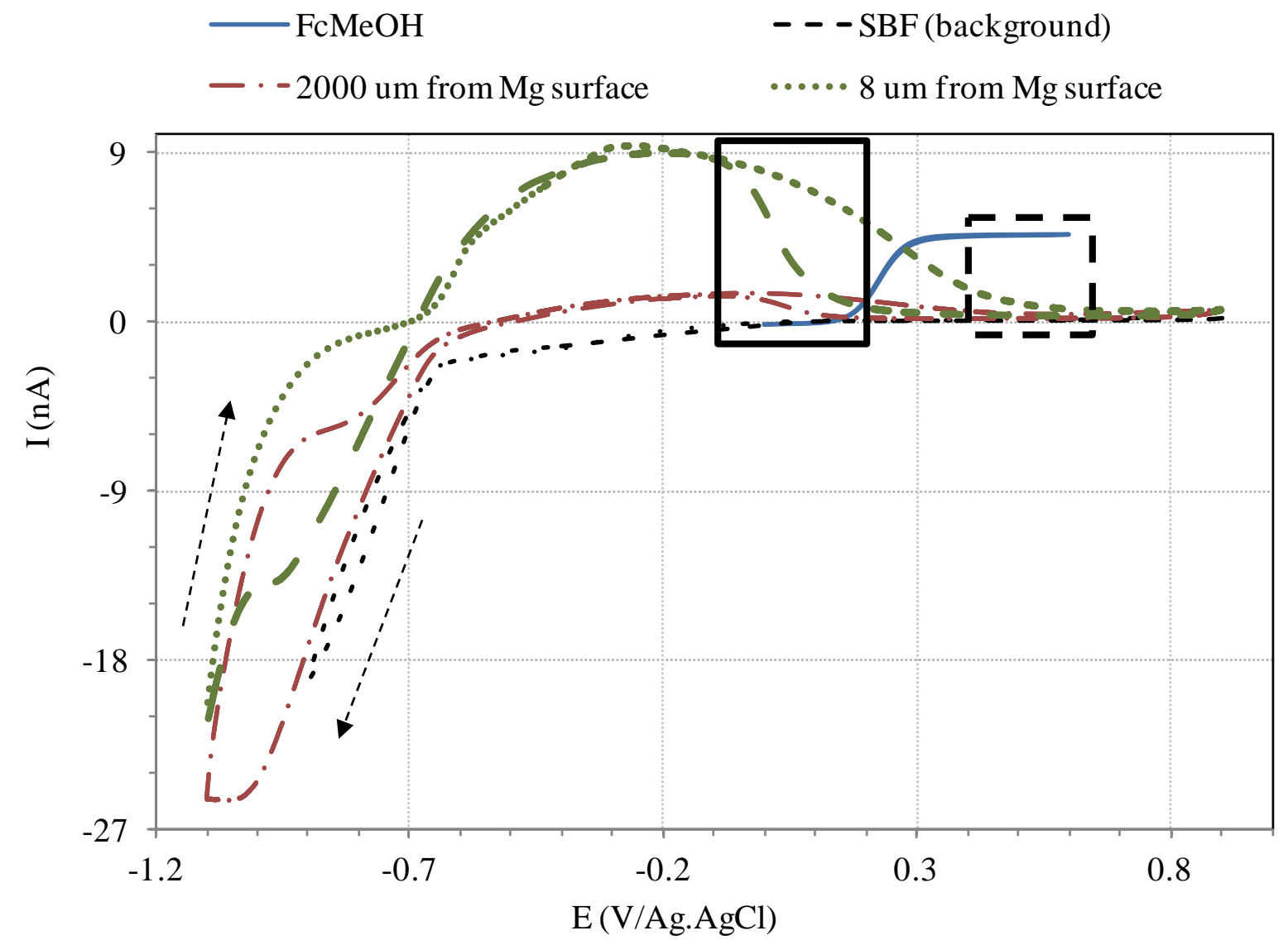

Figure 4 Cyclic voltammograms of a $10 \mu \mathrm{m}$ Pt UME in SBF showing the redox behaviour of the redox mediator FcMeOH compared with the probe current generated by $\mathrm{H}_{2}$ oxidation. Solid line box represents the potential window in which $\mathrm{H}_{2}$ evolution can be measured using SG/TC mode whilst the dash box represents the potential window in which the FcMeOH redox mediator can be detected in feedback mode. SBF background was obtained with fresh $\mathrm{SBF}$ and no Mg present in the solution. The concentration of FcMeOH in SBF was $4.0 \mathrm{mM}$. 


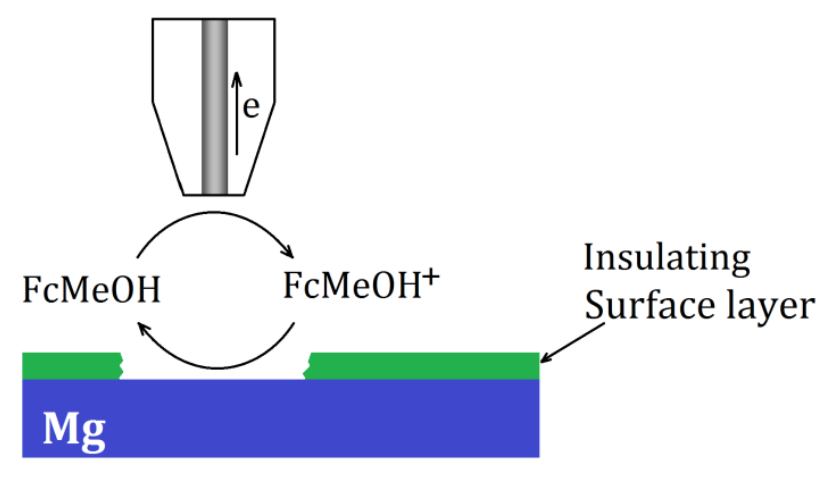

Figure 5 Schematic representation of SECM probe in feedback mode of operation showing redox activity of ferrocenemethanol $(\mathrm{FcMeOH})$ in contact with $\mathrm{Mg}$ substrate and cathodically biased Pt UME.
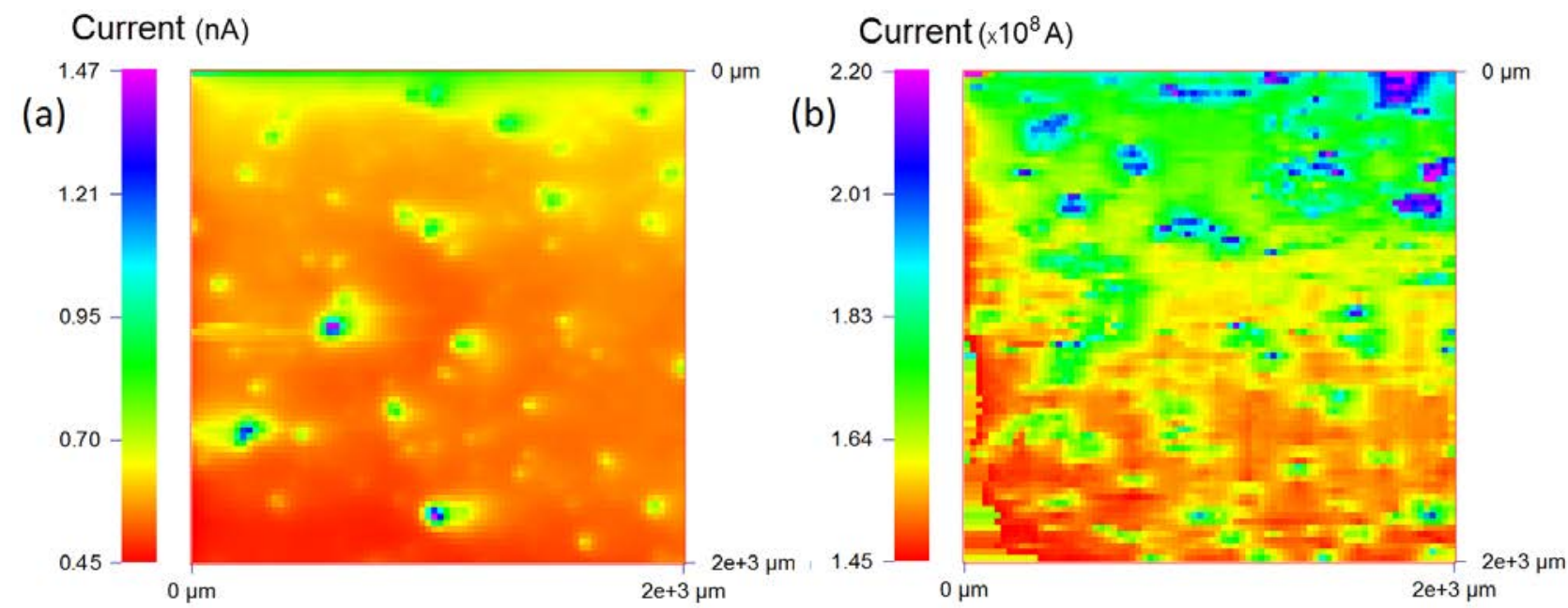

Figure 6 SECM images of AZ31 surface in SG/TC (a) and feedback (b) modes acquired via sensing the $\mathrm{H}_{2}$ evolution and $\mathrm{FcMeOH}(4 \mathrm{mM})$ regeneration. The tip potential in feedback mode was $0.55 \mathrm{~V}$ (vs. Ag/AgCl) and in SG/TC mode was $0.0 \mathrm{~V}$ (vs. Ag/AgCl). Both images

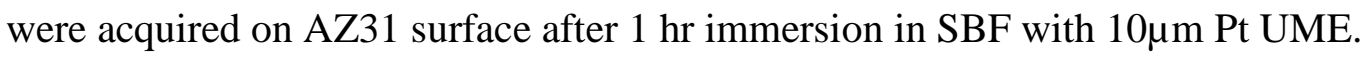




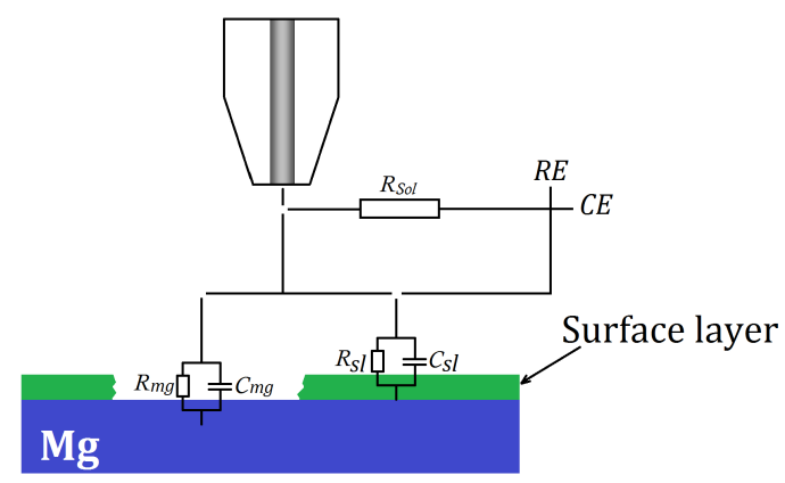

Figure 7 Schematic of the electrical model of AC mode data acquisition at conducting and insulating regions of an $\mathrm{Mg}$ surface.

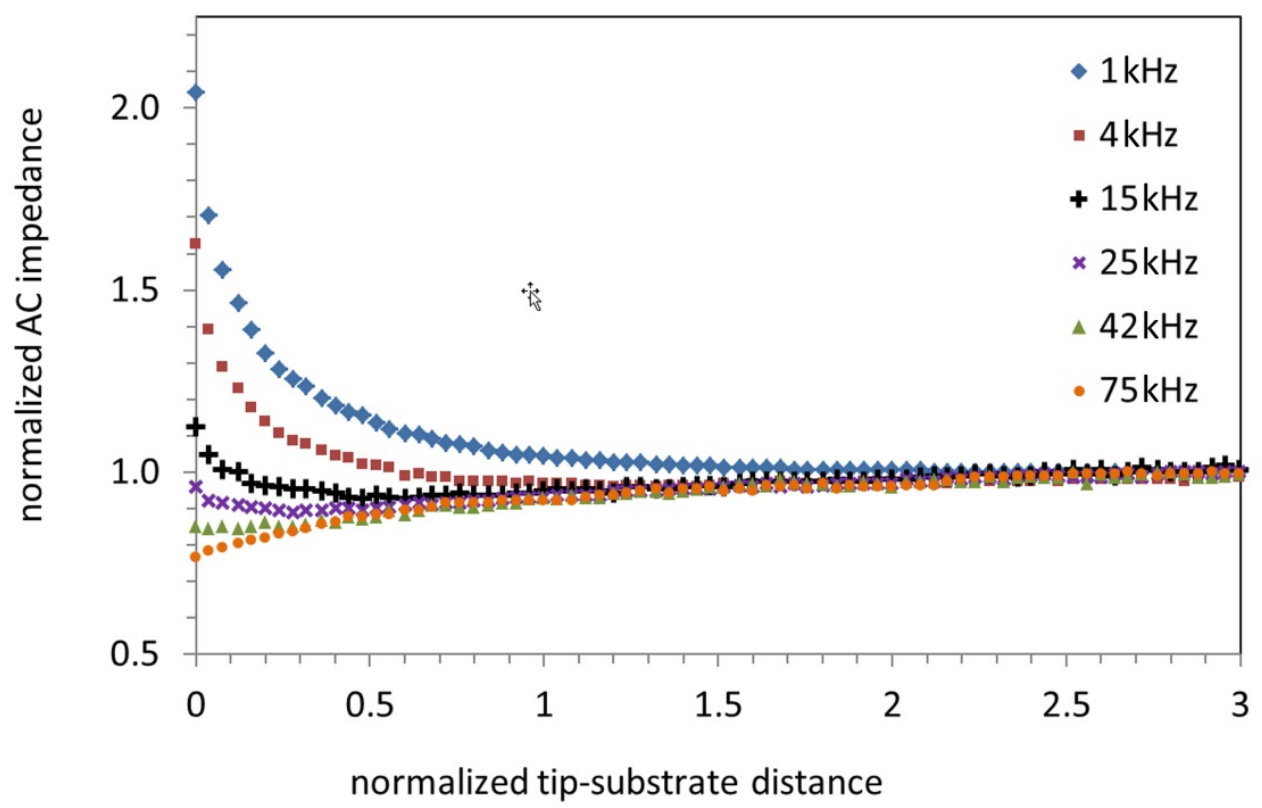

Figure 8 Normalized approach curves at the range of frequency from $75 \mathrm{kHz}$ to $1 \mathrm{kHz}$ towards the surface of AZ31 in diluted SBF. AZ31 was at open circuit potential. The probe was a $25 \mu \mathrm{m}$ diameter Pt UME held at OCP with excitation signal amplitude of $\pm 100 \mathrm{mV}$. 

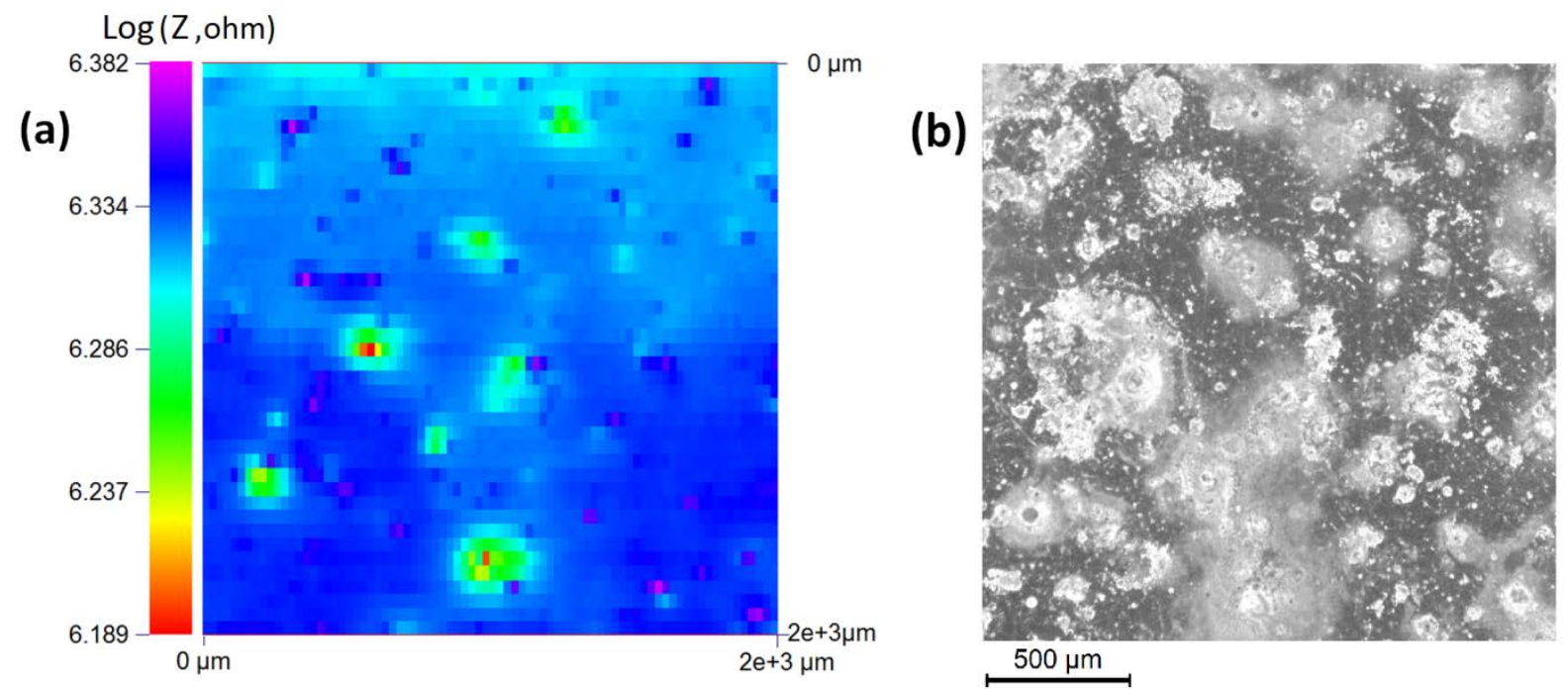

Figure 9 AC-SECM image (a) and optical micrograph (b) of AZ31 after $1 \mathrm{hr}$ immersion in SBF. AC mode experiments were performed in diluted SBF using a $25 \mu \mathrm{m}$ Pt UME with excitation signal amplitude of $100 \mathrm{mV}$ at $1 \mathrm{kHz}$.
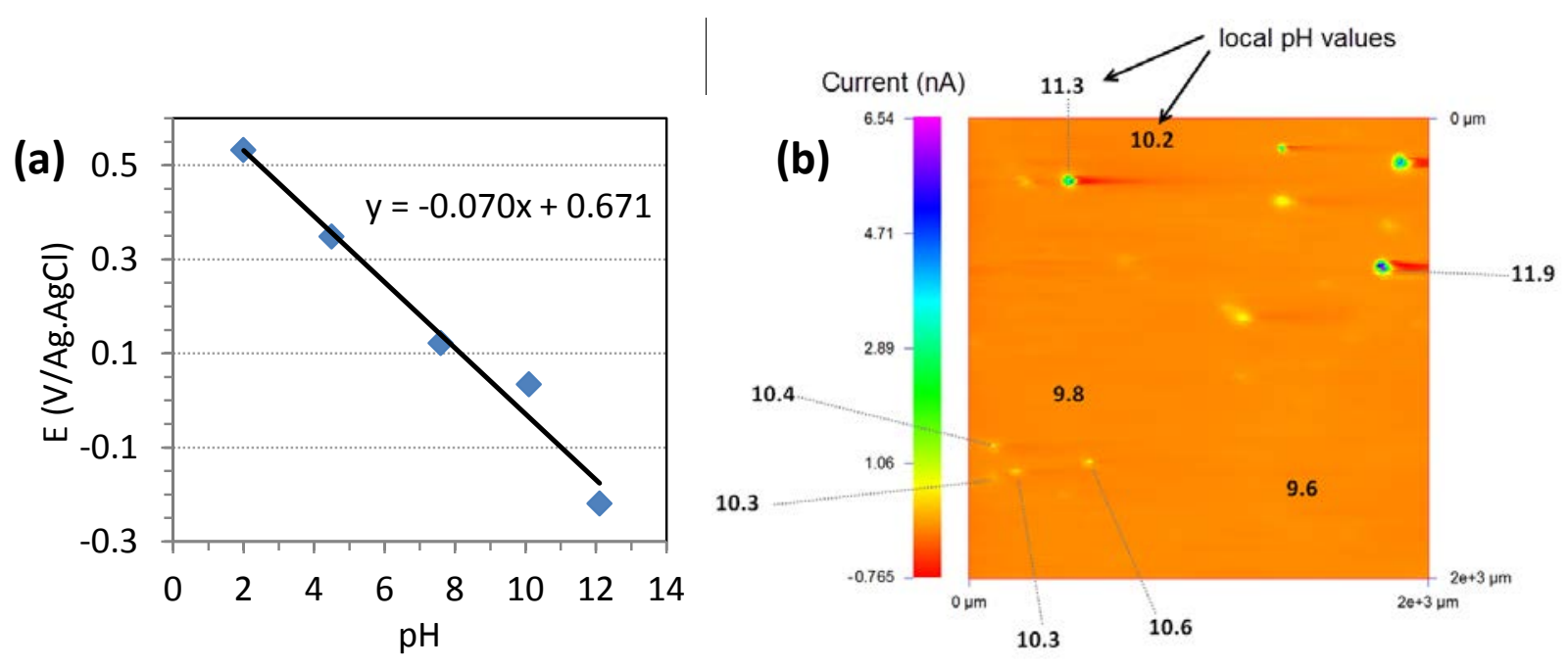

|Figure 10 Calibration curve correlating $\mathrm{Ir} / \mathrm{IrOx}$ potential to the $\mathrm{pH}$ of solution (a) and the local (single point) $\mathrm{pH}$ values shown on a $\mathrm{H}_{2}$ map (b). Ir/IrOx UME was positioned precisely above points of interest and OCP potential was recorded against Ag/AgCl. Individual $\mathrm{pH}$ values were converted from OCP values using the calibration graph. 